\title{
The validity of central venous to arterial carbon dioxide difference to predict adequate fluid management during living donor liver transplantation. A prospective observational study
}

Mohamed ElAyashy ${ }^{1}$, Hisham Hosny ${ }^{1,2^{*}}$ (D, Amr Hussein ${ }^{1}$, Ahmed AbdelAal Ahmed Mahmoud ${ }^{3}$, Ahmed Mukhtar ${ }^{1}$, Amira El-Khateeb ${ }^{1,2}$, Mohamed Wagih ${ }^{1}$, Fawzia AboulFetouh ${ }^{1}$, Amr Abdelaal ${ }^{4}$, Hany Said ${ }^{4}$ and Mostafa Abdo ${ }^{4}$

\begin{abstract}
Background: To assess the validity of central and pulmonary veno-arterial $\mathrm{CO}_{2}$ gradients to predict fluid responsiveness and to guide fluid management during liver transplantation.

Methods: In adult recipients (ASA III to IV) scheduled for liver transplantation, intraoperative fluid management was guided by pulse pressure variations (PPV). PPV of $\geq 15 \%$ (Fluid Responding Status-FRS) indicated fluid resuscitation with $250 \mathrm{ml}$ albumin 5\% boluses repeated as required to restore PPV to $<15 \%$ (Fluid non-Responding Status-FnRS). Simultaneous blood samples from central venous and pulmonary artery catheters (PAC) were sent to calculate central venous to arterial $\mathrm{CO}_{2}$ gap [C(v-a) $\mathrm{CO} 2$ gap] and pulmonary venous to arterial $\mathrm{CO}_{2}$ gap $[\mathrm{Pulm}(\mathrm{p}-\mathrm{a}) \mathrm{CO} 2$ gap] . $\mathrm{CO}$ and lactate were also measured.
\end{abstract}

Results: Sixty seven data points were recorded (20 FRS and 47 FnRS). The discriminative ability of central and pulmonary $\mathrm{CO}_{2}$ gaps between the two states (FRS and FnRS) was poor with AUC of ROC of 0.698 and 0.570 respectively. Central $\mathrm{CO}_{2}$ gap was significantly higher in FRS than FnRS $(P=0.016)$, with no difference in the pulmonary $\mathrm{CO}_{2}$ gap between both states. The central and Pulmonary $\mathrm{CO}_{2}$ gaps are weakly correlated to PPV $\left[r=0.291\right.$, $(P=0.017)$ and $r=0.367,(P=0.002)$ respectively]. There was no correlation between both $C_{2}$ gaps and both $\mathrm{CO}$ and lactate.

Conclusion: Central and the Pulmonary $\mathrm{CO}_{2}$ gaps cannot be used as valid tools to predict fluid responsiveness or to guide fluid management during liver transplantation. $\mathrm{CO}_{2}$ gaps also do not correlate well with the changes in PPV or CO.

Trial registration: Clinicaltrials.gov Identifier: NCT03123172. Registered on 31-march-2017.

Keywords: Central CO2 gap, Pulmonary CO2 gap, Liver transplantation, Fluid resuscitation

\footnotetext{
* Correspondence: hishamhosny@kasralainy.edu.eg

Article presented as poster in international liver transplant congress Czech

2017

'Department of Anesthesia and Intensive Care, Kasr Al-Ainy Faculty of

Medicine, Cairo University, Kasr Al-Ainy Street, Cairo, Egypt

2Department of Anaesthesia and Intensive care, Royal Brompton Hospital,

RBHT, Sydney Street, London SW3 6NP, UK

Full list of author information is available at the end of the article
}

(c) The Author(s). 2019 Open Access This article is distributed under the terms of the Creative Commons Attribution 4.0 International License (http://creativecommons.org/licenses/by/4.0/), which permits unrestricted use, distribution, and reproduction in any medium, provided you give appropriate credit to the original author(s) and the source, provide a link to the Creative Commons license, and indicate if changes were made. The Creative Commons Public Domain Dedication waiver (http://creativecommons.org/publicdomain/zero/1.0/) applies to the data made available in this article, unless otherwise stated. 


\section{Background}

End-stage liver disease (ESLD) patients undergoing orthotopic liver transplantation can be prone to severe hemodynamic and metabolic changes. In the dissection phase; bleeding and hypovolemia are frequent [1], while in the an-hepatic period venous return may decrease resulting in a reduction in left ventricular preload [2] while after de-clamping and starting the neo-hepatic phase, the reperfusion injury and metabolic derangement can be severe enough to cause serious consequences [3].

Adequate tissue perfusion is an essential component of oxygenation during high-risk surgery and may improve the outcome $[4,5]$. Proper monitoring of fluid resuscitation has been shown to reduce organ failure and hospital stay $[6,7]$. The early warning signals of tissue hypoxia, such as lactate, central venous to arterial $\mathrm{CO}_{2}$ gradient and central venous oxygen saturation $\left(\mathrm{ScvO}_{2}, 8\right]$, are essential indicators of the changes in the $\mathrm{O}_{2}$ delivery/consumption $\left(\mathrm{DO}_{2} / \mathrm{VO}_{2}\right)$ relationship during high-risk surgery [8-10].

The difference between $\mathrm{PCO}_{2}$ in mixed venous blood $\left(\mathrm{PvCO}_{2}\right)$ and $\mathrm{PCO}_{2}$ in arterial blood $\left(\mathrm{PaCO}_{2}\right)$ is defined as the mixed venous-to-arterial $\mathrm{CO}_{2}$ tension gap [Pulm (P-a) $\mathrm{CO}_{2}$ ] and is affected by cardiac output and global $\mathrm{CO}_{2}$ production, as well as the complex relationship between $\mathrm{PCO}_{2}$ and $\mathrm{CO}_{2}$ content [11]. Normally, Pulm(P-a) $\mathrm{CO}_{2}$ does not exceed $6 \mathrm{mmHg}$. Elevated [Pulm(P-a) $\mathrm{CO}_{2}$ ] gradient has been observed in all types of circulatory failure (cardiogenic, obstructive, hypovolemic and distributive shock) [12].

Pulse Pressure Variation (PPV) is derived from the analysis of the arterial pulse waveform and is currently integrated in many monitors and is used as a valid tool to predict fluid responsiveness and to guide fluid management during liver transplantation [13].

To the best of our knowledge, no previous study assessed the ability of the Central $\mathrm{CO}_{2}$ gap or Pulmonary $\mathrm{CO}_{2}$ gap to predict fluid responsiveness and to guide optimization of fluid status during liver transplantation.

Our study aimed to assess the ability of the Central and Pulmonary $\mathrm{CO}_{2}$ gaps to guide adequate fluid management during liver transplantation. We hypothesize that $\mathrm{CO}_{2}$ gaps can be a complementary tool to PPV to guide adequate fluid management.

\section{Methods}

This prospective observational study was approved by the Research Ethics Committee of Kasr Al-Ainy faculty of medicine, Cairo University (N-21-2017) and written informed consents was obtained from all study participants. The trial was registered prior to patient enrollment at clinicaltrials.gov (NCT03123172).

The study was designed to include 20 adult ( $>18$ years) ASA III to IV physical status patients with an end-stage liver disease (ESLD) scheduled for orthotopic liver transplantation. Patients were excluded if they were less than 18 years old or suffering from chronic respiratory disease. Induction of anesthesia was performed using propofol, fentanyl, and atracurium and maintained with sevoflurane adjusted to achieve an expired minimal alveolar concentration (MAC) between 1 and $2 \%$ in a mixture of air/oxygen, fentanyl infusion $(1-2 \mu \mathrm{g} / \mathrm{kg} / \mathrm{h})$, and atracurium infusion $(0.5 \mathrm{mg} / \mathrm{kg} / \mathrm{h})$. Patients were mechanically ventilated (Dräger Primus ${ }^{\oplus}$, Germany) with a $6-8 \mathrm{ml} / \mathrm{kg}$ tidal volume and respiratory rate adjusted to maintain the $\mathrm{ETCO}_{2}$ between 4 and $4.6 \mathrm{kPa}$ and positive end expiratory pressure (PEEP) of $5 \mathrm{cmH}_{2} \mathrm{O}$. Patients monitoring included five-lead ECG, pulse oximetry, invasive arterial blood pressure, core temperature, $\mathrm{ETCO}_{2}$, hourly UOP, and central venous pressure (CVP). A 7-Fr triple lumen CV catheter (Arrow International Inc., Reading, PA, USA) and an 8.5Fr pulmonary artery catheter sheath were placed in the right internal jugular vein and a pulmonary artery catheter (OPTIQ $\mathrm{SVO}_{2} /$ CCO; Abbott Laboratories, North Chicago, IL, USA) was positioning guided by chamber pressures and confirmed with fluoroscopy. All patients received $6 \mathrm{ml} /$ $\mathrm{kg}$ crystalloids as maintenance intraoperative fluid. Pulse pressure variations (PPV) [Philips Intellivue MP50 monitor (Philips Medical Systems, BG Eindhoven, The Netherlands)] used to guide intraoperative fluid management. If pulse pressure variation (PPV) was more than $15 \%$, the patient was considered as a fluid responder and received a $250-\mathrm{ml}$ boluses of $5 \%$ albumin to maintain $\leq 15 \%$ PPV Arterial, central venous and pulmonary artery blood samples were collected and analyzed (ABL 300, Radiometer Copenhagen, Denmark). We calculated the central venous to arterial $\mathrm{CO}_{2}$ gap $\left[\mathrm{C}(\mathrm{v}-\mathrm{a}) \mathrm{CO}_{2}\right]$ and the pulmonary mixed venous to arterial $\mathrm{CO}_{2}$ gap $[\mathrm{Pulm}(\mathrm{P}-\mathrm{a})$ $\mathrm{CO}_{2}$ ] at two time periods, $30 \mathrm{~min}$ after the start of the pre-anhepatic dissection phase and $30 \mathrm{~min}$ after the reperfusion of the transplanted graft. No data was recorded during the an-hepatic phase or during partial or complete obstruction of the IVC by either clamping or surgical manipulation.

A transfusion trigger of $7 \mathrm{~g} / \mathrm{dL}$ guided the need for blood transfusion while. Fresh frozen plasma and platelets were transfused if the INR reached $>1.5$ and the count was $<50,000 / \mu \mathrm{l}$ respectively guided by thromboelastography and according to the severity of bleeding.

Patient characteristics; age, weight, MELD Score, child score and associated $\mathrm{HCC}$ were recorded. Intraoperatively central $\mathrm{CO}_{2}$ and pulmonary $\mathrm{CO}_{2}$ gaps were recorded apart from during the anhepatic phase and IVC obstruction as described earlier. Cardiac output (CO), lactate, central venous oxygen saturation $\left(\mathrm{ScvO}_{2}\right)$ and PPV were all recorded throughout the procedures. 
Primarily, the current study aimed to investigate the ability of $\mathrm{CO}_{2}$ gaps to predict fluid responsiveness appreciated by PPV. Area Under the Curve (AUC) for Receiver Operating Characteristic (ROC) was used to calculate the discriminative ability of both $\mathrm{CO}_{2}$ gaps to distinguish between FRS and FnRS with calculation of a cutoff value for either $\mathrm{CO}_{2}$ gaps should it be existing.

Secondarily, a comparison between central and pulmonary $\mathrm{CO}_{2}$ gaps in both fluid states (FRS and FnRS), the correlation of the $\mathrm{CO}_{2}$ gaps to the hemodynamic and metabolic parameters (PPV, CO and lactate), the correlation between hemodynamic and metabolic parameters (CO and lactate) and fluid responsiveness (FRS and FnRS) were also studied.

\section{Sample size calculation}

The sample size was calculated after obtaining preliminary data of seven fluid non-responding status data points, which revealed a mean (SD) of the central $\mathrm{CO}_{2}$ gap to be3.8 (1.7). Assuming a mean difference of $30 \%$ between responding and non-responding and by using $\mathrm{G}$ power software (version 3.1.3, Heinrich-Heine-Universität, Düsseldorf Germany) with a power of 0.8 and 0.05 alpha error sample size was calculated to be 20 patients.

\section{Statistical analysis}

Central and pulmonary $\mathrm{CO}_{2}$ gaps, cardiac output and lactate level are presented as mean (SD). Mann-Whitney test was performed for comparison of cardiac output and the Central and the Pulmonary $\mathrm{CO}_{2}$ gaps. The Receiver Operating Characteristic (ROC) curves were constructed, and the area under the curve (AUC) calculated to compare the performance of the central $\mathrm{CO}_{2}$ gap and the pulmonary $\mathrm{CO}_{2}$ gap in predicting fluid responsiveness. MedCalc version 12.1.4.0 (MedCalc Software bvba, Mariakerke, Belgium) generated values with the highest sensitivity and specificity (Youden index). Comparison of the AUC of the ROC curves used a Hanley-McNeil test. Correlations between either central $\mathrm{CO}_{2}$ gap and pulmonary $\mathrm{CO}_{2}$ gap and each of $\mathrm{CO}$, lactate and PPV were done using Pearson moment correlation equation. A $P$ value of less than 0.05 was considered statistically significant. All but ROC curves statistical calculations were done using SPSS (Statistical Package for the Social Science; SPSS Inc., Chicago, IL, USA) statistical program.

\section{Results}

Twenty patients (16 males and 4 females) were enrolled in the study. Their mean (SD) age was 53.1(7.6) years, mean (SD) weight 79.2 (11.5) kg, and mean (SD) height $170.1(7.2) \mathrm{cm}$. Thirteen patients had ESLD following hepatitis $\mathrm{C}$, two patients had a hepatocellular carcinoma (HCC), and five patients had combined hepatitis $\mathrm{C}$ and HCC. Median (range) of MELD score was 17 (13-29). Fourteen patients had a child-class $C$, and six patients had a child-class $B$ and fifteen patients presented with ascites. There were 67 data points recorded (20 FRS points and $47 \mathrm{FnRS}$ points).

Mean values of central $\mathrm{CO}_{2}$ gap, pulmonary $\mathrm{CO}_{2}$ gap, lactate, $\mathrm{ScvO}_{2}$, and $\mathrm{CO}$ are presented in Table 1. Central $\mathrm{CO}_{2}$ gap was significantly higher in fluid-responder compared to the fluid non-responders $(P=0.016)$. Lactate level, $\mathrm{ScvO}_{2}$, pulmonary $\mathrm{CO}_{2}$ and $\mathrm{CO}$ were comparable between both FRS and FnRS.

A correlation was found between the central $\mathrm{CO}_{2}$ gap and PPV $(r=0.291, P=0.017)$ (Fig. 1) and between the pulmonary $\mathrm{CO}_{2}$ gap and the PPV $(\mathrm{r}=0.367$ and $P=$ 0.002) (Fig. 2).

The ROC for the central $\mathrm{CO}_{2}$ gap and pulmonary $\mathrm{CO}_{2}$ gap to predict fluid responsiveness was 0.698 and 0.570 respectively. From ROC curve, the optimal cutoff value 3.6 was determined for the central $\mathrm{CO}_{2}$ gap to predict fluid responsiveness with sensitivity $83 \%$ and specificity $55 \%$ (Fig. 3).

There was no correlation between central $\mathrm{CO}_{2}$ gap and $\mathrm{CO}(\mathrm{r}=0.168, P=0.17)$ or between pulmonary $\mathrm{CO}_{2}$ gap and $\mathrm{CO}(\mathrm{r}=0.22)$ with $P=0.076$. Also, there was no correlation between either central or pulmonary $\mathrm{CO}_{2}$ gap and the lactate level $(r)=0.071$ and 0.202 respectively.

\section{Discussion}

The target of the current study was to answer three questions; first, are the central and the pulmonary $\mathrm{CO}_{2}$ gaps valid indicators of fluid responsiveness in liver transplant patients? And is there a difference between

Table 1 Comparison between fluid responding status (FRS) and Fluid non-Responding Status (FnRS). Values presented as Mean (SD)

\begin{tabular}{llll}
\hline & Fluid Responding Status $(N=20)$ & Fluid non-Responding Status $(N=47)$ & $P$ value \\
\hline $\mathrm{C}\left(\mathrm{v}\right.$-a) $\mathrm{CO}_{2}$ gap & $5.5(2.6)$ & $4.3(3.2)^{*}$ & 0.016 \\
Pulm $(\mathrm{P}-\mathrm{a}) \mathrm{CO}_{2}$ gap & $5.16(4.24)$ & $3.96(2.89)$ & 0.18 \\
Lactate & $3.9(1.6)$ & $3.5(2.3)$ & 0.18 \\
$\mathrm{CO}$ & $6.7(2.6)$ & $8.8(3.4)$ & 0.06 \\
$\mathrm{SCVO}_{2}$ & $80.3(12.1)$ & $82.5(11.9)$ & 0.32 \\
\hline
\end{tabular}

${ }^{*} P$ value $=0.016$ with significant difference between two groups. Mann Whitney test. $N$ Number of data points, $C(v-a) C O 2$ central venous to arterial carbon dioxide tension difference, $P$ ulm $(P-a) C O 2$ mixed venous to arterial carbon dioxide tension difference, $\mathrm{CO}$ cardiac output, Scvo2 central venous oxygen saturation 


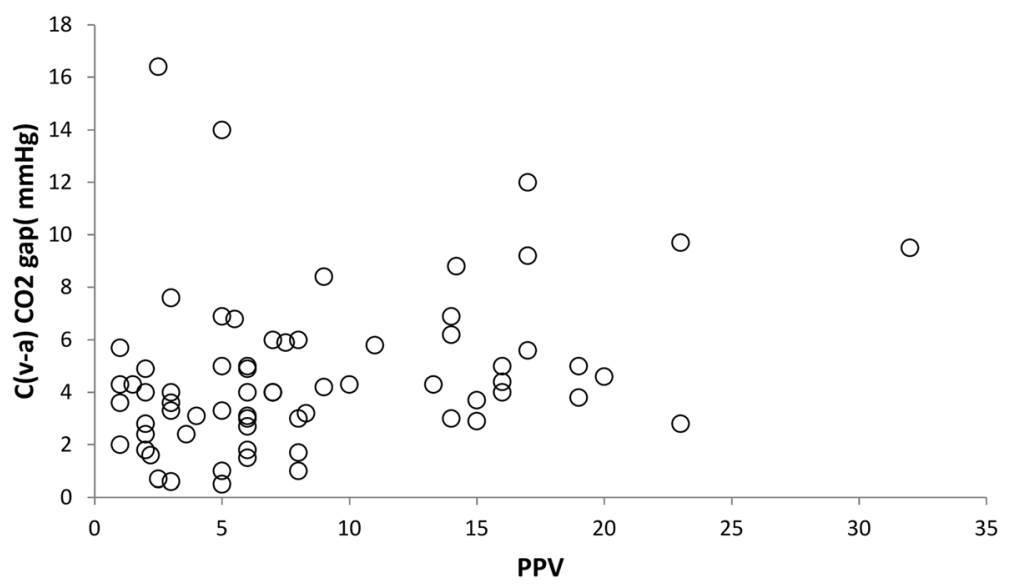

Fig. 1 Correlation between PPV and $C(v-a) C O 2$ gap. $C(v-a) C O 2$; Central venous to arterial carbon dioxide tension difference, PPV; pulse pressure variation

the central and the pulmonary $\mathrm{CO}_{2}$ gaps in this setting? Second, do central and pulmonary $\mathrm{CO}_{2}$ gaps correlate with other hemodynamic and metabolic parameters such as CO, PPV and lactate? Third, are there any differences between fluid responding and fluid non-responding states in the hemodynamic and metabolic parameters?

For the first question, there were two main findings; (1) central $\mathrm{CO}_{2}$ gap was significantly higher in FRS than in FnRS during the pre- and post anhepatic phase of liver transplantation surgery, however the ability of the central $\mathrm{CO}_{2}$ gap to predict fluid responsiveness was weak (AUC $=0.698)$ and the cutoff gap value to predict fluid responsiveness was $3.6 \mathrm{mmHg}$. On the other hand, the pulmonary $\mathrm{CO}_{2}$ gap was comparable between FRS and FnRS. (2) Both central and pulmonary $\mathrm{CO}_{2}$ gaps were comparable $(4.65 \pm 2.996$ versus $4.31 \pm 3.34$ respectively, $P=0.405)$ and both showed significant correlation $(\mathrm{r}=0.444, P$ value $=0.0001)$. Possibly this contradiction between the two findings is the result of the presence of intrapulmonary shunt [14] in our patients characterized by cirrhosis and the high-risk present of hepatopulmonary syndrome [15]. The similarity in hemodynamic pathophysiology between our patients and septic shock patients explains the agreement between our results and the previous findings of the use of $\mathrm{CO}_{2}$ gap in cases of septic shock, both gaps cannot be used alone as valid indicators of fluid responsiveness despite the central $\mathrm{CO}_{2}$ gap in our patients being higher in fluid responder, but the diagnostic validity of which remained weak. Based on our findings, veno-arterial $\mathrm{CO}_{2}$ gap cannot be relied upon as a tool to predict fluid responsiveness in these patients with complex hemodynamic and pathophysiological changes. Additionally, both $\mathrm{CO}_{2}$ gaps (central and pulmonary) are approximate and the central $\mathrm{CO}_{2}$ gap can replace the pulmonary [16-22].

Answering the second question, both $\mathrm{CO}_{2}$ gaps were only correlated with PPV but not with cardiac output or lactate level. PPV is a validated monitor for prediction of fluid responsiveness in major abdominal surgeries [13] however, the correlation of the $\mathrm{CO}_{2}$ gaps with PPV,

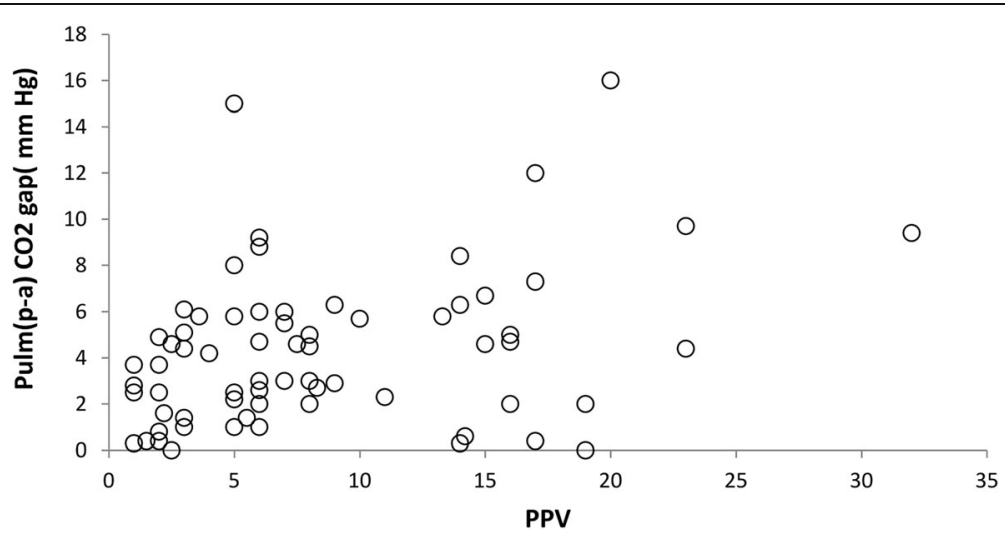

Fig. 2 Correlation between PPV and Pulm(pv-a) CO2 gap. Pulm(p-a) CO2; mixed venous to arterial carbon dioxide tension difference, PPV; pulse pressure variation 


\section{ROC Curve}

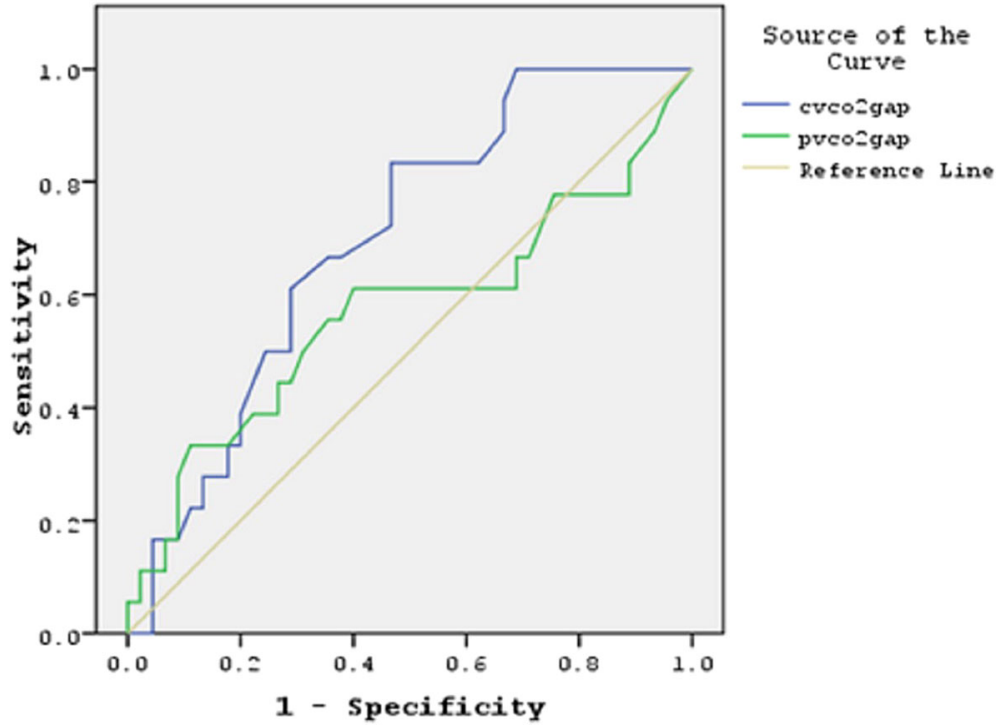

Fig. 3 ROC curve of $C(v-a) C O 2$ gap and Pulm(pv-a) CO2 gap. $C(v-a) C O 2$; central venous to arterial carbon dioxide tension difference, Pulm(p-a) $\mathrm{CO}$; mixed venous to arterial carbon dioxide tension difference

despite being significant, was weak. This supports our finding that the $\mathrm{CO}_{2}$ gaps cannot be used alone as a valid predictors of fluid responsiveness in liver transplant patients.

Lactate level reflects both tissue anaerobic metabolism and the ability of the liver to metabolize it, with both conditions present in liver transplant patients during different phases of the transplant procedure (hepatic dissection, an-hepatic and neo-hepatic phases). Lactate level is a validated parameter to monitor adequate fluid resuscitation and the absent correlation between lactate and the $\mathrm{CO}_{2}$ gap in our patients supports the disputed validity of $\mathrm{CO}_{2}$ gaps as sole monitor of fluid responsiveness. Mekontso et al. [23] confirmed the correlation between $\mathrm{CO}_{2}$ gap and lactate level during hypoxic metabolic states with decreased oxygen consumption. Mekontso et al. used the ratio, rather than the absolute value, of $\mathrm{CO}_{2}$ gap to arterio-venous oxygen difference to relate to lactate levels.

For a constant total $\mathrm{CO}_{2}$ production $\left(\mathrm{VCO}_{2}\right)$, changes in cardiac output result in large changes in pulmonar$\mathrm{yCO}_{2}$ gap at low cardiac output values, whereas changes in cardiac output will not result in significant changes in pulmonary $\mathrm{CO}_{2}$ gap at the high values of cardiac output $[22,24]$ This relation supports our finding of the absence of correlation between $\mathrm{CO}_{2}$ gaps and the $\mathrm{CO}$ in our patients known to have a high $\mathrm{CO}$ as part of the pathophysiology of liver cirrhosis.

Moving forward to the third question, FRS and FnRS patients were comparable regarding their lactate level, pulmonary $\mathrm{CO}_{2}$ gap and $\mathrm{CO}$. These findings support the verdict not to rely only on $\mathrm{CO}_{2}$ gaps alone as valid indicators of fluid responsiveness.

In our study, both central and pulmonary $\mathrm{CO}_{2}$ gaps correlated with PPV. Cuschieri et al. [25] and Van Beest PA et al. [26] showed strong agreement between central and pulmonary $\mathrm{CO}_{2}$ gaps in their studies of critically ill patients and on septic patients. In the current study, there was no correlation between central and pulmonary $\mathrm{CO}_{2}$ gaps with cardiac output., many studies [12, 25, 27] stated an increased central $\mathrm{CO}_{2}$ gap in low cardiac output states due to venous flow stasis which decreased with increased cardiac output. Cuschieri et al. [25] showed the correlation between the central $\mathrm{CO}_{2}$ gap and the pulmonary $\mathrm{CO}_{2}$ gap with cardiac index. Troskot et al. [12] concluded in their study of patients with severe sepsis and septic shock that the central $\mathrm{CO}_{2}$ gradient could predict fatal outcomes in non-ventilated patients only. Also, Mallat et al. [11] in their study on 80 patients with sepsis, measured the central $\mathrm{CO}_{2}$ gap and cardiac index using PICCO technology at time 0 (start of the study) and at time 6 ( $6 \mathrm{~h}$ after resuscitation) and found a correlation between $\mathrm{CO}_{2}$ gap and $\mathrm{CI}$ at $\mathrm{T0}(\mathrm{r}=-0.69$, $P<0.0001)$ and at T6 $(\mathrm{r}=-0.54 P<0.0001)$. Also, the changes in $\mathrm{CI}$ between $\mathrm{T} 0$ and $\mathrm{T} 6$ were also correlated with changes in $\mathrm{CO}_{2}$ gap $(\mathrm{r}=-0.62, P<0.0001)$.

In our study, the central $\mathrm{CO}_{2}$ gap did not correlate with cardiac output presumably due to the hyperdynamic state of the hepatic patient which preserves systemic blood flow even in states of tissue hypo-perfusion. Mecher et al. [28] studied 37 septic patients divided into two groups according to the central $\mathrm{CO}_{2}$ gap; high gap 
group $>6 \mathrm{mmhg}$ and normal gap group $<6 \mathrm{mmHg}$. They found normal gap group to have a high cardiac index $(3 \pm 0.2)$ despite circulatory failure. In this group; the gap did not change after fluid resuscitation (pre-fluid gap $4 \pm 0$ vs. post fluid $4 \pm 1 \mathrm{mmHg}$ ) with an increase in cardiac index. While in the other group cardiac index was lower $(2.3 \pm 0.2)$ and gap decreased after resuscitation.

In our results, there was no correlation between either central $\mathrm{CO}_{2}$ gap or pulmonary $\mathrm{CO}_{2}$ gap and the lactate level. This was consistent with the study of Vallee et al. [29] in which 50 patients with septic shock, hyperlactatemia $>2 \mathrm{mmol} / \mathrm{L}$ and $\mathrm{ScvO} 2>70 \%$ were enrolled. $\mathrm{Pa}$ tients were divided into two groups according to central $\mathrm{CO}_{2}$ gap with cut off value of $6 \mathrm{mmHg}$, low gap $(<6$ $\mathrm{mmHg}$ ), and high gap ( $>6 \mathrm{mmHg})$. Patients' resuscitation resulted in significantly larger clearance of lactate in low gap group than high gap group. There was also no correlation between $\mathrm{CvCO}_{2}$ gap and lactate level at time of inclusion T0 $(\mathrm{r}=0.17, P=0.22$. $)$ and poor correlation at six hours T6 $(\mathrm{r}=0.37, P=0.003)$ and twelve hours T12 ( $\mathrm{r}=0.36, P=0.008)$.

In agreement with our results, Monnet et al. [30] found that volume expansion in all patients increased cardiac index and there was correlation between pulmonary $\mathrm{CO}_{2}$ gap and cardiac index at baseline ( $\mathrm{r}=-0.36, p=0.0002)$ but not between pulmonary $\mathrm{CO}_{2}$ gap and lactate at baseline $(p=0.58)$. Also, Mecher et al. [28] showed no significant decrease in Pulmonary $\mathrm{CO}_{2}$ gap and lactate after fluid resuscitation in all patients with severe sepsis and systemic hypo-perfusion involved in the study.

fCO2 gap was found to be complementary tool for early resuscitation of patients with circulatory failure [31]. In the present study, despite the presence of significant difference in the central $\mathrm{CO}_{2}$ gap between fluid responding and non-responding states, the validity of CO2 gap is poor which makes its use to guide fluid resuscitation in liver transplant recipient is questionable.The present study had several limitations. First, This is a single center experience. Second, we avoided periods of marked hemodynamic instability caused by manipulation of the liver and downward retraction of the inferior vena cava which may intermittently obstruct venous return and causing hemodynamically significant changes in preload. Such changes in the preload are typically transient and may not reflect the actual volume status of the patient. Finally, we did not compare the $\mathrm{CO}_{2}$ gaps recorded during the pre-anhepatic phase to the $\mathrm{CO}_{2}$ gaps recorded during the neo-hepatic phase as the two periods represent different hemodynamic and pathophysiologic situations with the presence of a cirrhotic liver in the former and a potentially healthy graft in the latter. A future study can check this aspect.

\section{Conclusion}

Both central $\mathrm{CO}_{2}$ gap and pulmonary $\mathrm{CO}_{2}$ gaps could not be used to predict fluid responsiveness or to guide adequate fluid management during living related liver transplantation. Both $\mathrm{CO}_{2}$ gaps could be used interchangeably, and both did not correlate well with changes in cardiac output or lactate level. These results suggest that $\mathrm{CO}_{2}$ gap may not be a good hemodynamic endpoint of resuscitation of patients undergoing living related liver transplant.

\section{Abbreviations \\ ASA: American society of anesthesiologists; AUC: Area under the curve; $C(v-a)$ $\mathrm{CO}_{2}$ : Central $\mathrm{CO}_{2}$ gap; $\mathrm{CO}$ : Cardiac output; $\mathrm{CO}_{2}$ : Carbon dioxide; CVP: Central venous pressure; $\mathrm{DO}_{2} \mathrm{NO}_{2}: \mathrm{O}_{2}$ delivery/consumption; ECG: Electrocardiogram; ESLD: End-stage liver disease; $\mathrm{ETCO}_{2}$ : End tidal $\mathrm{CO}_{2}$; FnRS: Fluid non- responsive status; FRS: Fluid responsive status; HCC: Hepatocellular carcinoma; MAC: minimal alveolar concentration; PAC: Pulmonary artery catheter; $\mathrm{PaCO}_{2}$ : Arterial carbon dioxide pressure; $\mathrm{PCO}_{2}$ : Partial carbon dioxide pressure; PEEP: Positive end expiratory pressure; PPV: Pulse pressure variations; Pulm (P-a) $\mathrm{CO}_{2}$ : Mixed venous-to-arterial $\mathrm{CO}_{2}$ tension gap; $\mathrm{PVCO}_{2}$ : Mixed venous carbon dioxide pressure; ROC: Receiver Operating Characteristic; $\mathrm{SCVO}_{2}$ : Central venous oxygen saturation; UOP: Urine output}

\section{Acknowledgements}

$\mathrm{N} / \mathrm{A}$

\section{Authors' contributions}

$\mathrm{HH}$ : collected data and revised the manuscript. ME: collected data and wrote the initial manuscript and performed analysis. AH: collected data and wrote the initial manuscript and performed analysis. AM: revised manuscript and data analysis. AM: study design and revised the manuscript and data analysis FA: study design and revised the manuscript. AA: patient recruitment and revised the manuscript. HS: patient recruitment and revised the manuscript. MA: patient recruitment and revised the manuscript. AE: revised the manuscript and data analysis and replid to reviewers' comments. MW: revised the manuscript and data analysis and replied to reviewers' comments. All authors read and approved the final manuscript.

\section{Funding}

No external funding received.

Availability of data and materials

The datasets used and/or analysed during the current study are available from the corresponding author on reasonable request.

Ethics approval and consent to participate

Study has been approved by Kasr Al-Ainy faculty of medicine ethics committee, Cairo University. (N-21-2017). Written informed consents was obtained from all study participants.

\section{Competing interests}

The authors declare that they have no competing interests. $\mathrm{HH}$ is an associate editor in BMC anaesthesiology.

\section{Author details}

${ }^{1}$ Department of Anesthesia and Intensive Care, Kasr Al-Ainy Faculty of Medicine, Cairo University, Kasr Al-Ainy Street, Cairo, Egypt. ²Department of Anaesthesia and Intensive care, Royal Brompton Hospital, RBHT, Sydney Street, London SW3 6NP, UK. ${ }^{3}$ Department of Anesthesia and intensive care, Faculty of Medicine, Beni-Suef University, Beni-Suef, Egypt. ${ }^{4}$ Department of Surgery, Ain Shams University, Cairo, Egypt. 
Received: 23 November 2018 Accepted: 3 June 2019

Published online: 22 June 2019

\section{References}

1. Alkozai EM, Lisman T, Porte RJ. Bleeding in liver surgery: prevention and treatment. Clin Liver Dis. 2009;13:145-54.

2. Hoffmann K, Weigand MA, Hillebrand N, Büchler MW, Schmidt J, Schemmer $P$. Is veno-venous bypass still needed during liver transplantation? A review of the literature. Clin Transpl. 2009;23:1-8.

3. Lehmann C. Biochemie und Pathophysiologie von Ischämie und Reperfusion. DMW - Dtsch Medizinische Wochenschrift. 2009;134(S 11): S409-10.

4. Shoemaker WC, Appel PL, Kram HB. Role of oxygen debt in the development of organ failure Sepsis, and death in high-risk surgical patients. Chest. 1992;102:208-15.

5. Derikx JPM, Poeze M, van Bijnen AA, Buurman WA, Heineman E. Evidence for intestinal and liver epithelial cell injury in the early phase of sepsis. Shock. 2007;28(5):544-8 PAP.

6. Giglio MT, Marucci M, Testini M, Brienza N. Goal-directed haemodynamic therapy and gastrointestinal complications in major surgery: a meta-analysis of randomized controlled trials. Br J Anaesth. 2009;103:637-46.

7. Bundgaard-Nielsen $\mathrm{M}$, Holte $\mathrm{K}$, Secher $\mathrm{NH}$, Kehlet $\mathrm{H}$. Monitoring of perioperative fluid administration by individualized goal-directed therapy. Acta Anaesthesiol Scand. 2007:51:331-40.

8. Greenwood JC, Orloski CJ. End points of Sepsis resuscitation. Emerg Med Clin North Am. 2017:35:93-107.

9. JAKOB SM. Collaborative study group on perioperative ScvO_2 monitoring: multicentre study on peri- and postoperative central venous oxygen saturation in high-risk surgical patients. Crit Care. 2006;10:R158.

10. Pearse R, Dawson D, Fawcett J, Rhodes A, Grounds RM, Bennett ED. Changes in central venous saturation after major surgery, and association with outcome. Crit Care. 2005;9:R694.

11. Mallat J, Lemyze M, Tronchon L, Vallet B, Thevenin D. Use of venous-toarterial carbon dioxide tension difference to guide resuscitation therapy in septic shock. World J Crit care Med. 2016:5:47-56.

12. Troskot R, Šimurina T, Žižak M, Majstorović K, Marinac I, Šutić IM. Prognostic value of Venoarterial carbon dioxide gradient in patients with severe Sepsis and septic shock. Croat Med J. 2010;51:501-8.

13. Rathore A, Singh S, Lamsal R, Taank P, Paul D. Validity of pulse pressure variation (PPV) compared with stroke volume variation (SW) in predicting fluid responsiveness. Turkish J Anaesthesiol Reanim. 2017:45:210-7.

14. Khabbaza JE, Krasuski RA, Tonelli AR. Intrapulmonary shunt confirmed by intracardiac echocardiography in the diagnosis of hepatopulmonary syndrome. Hepatology. 2013;58:1514-5.

15. Rodríguez-Roisin R, Krowka MJ. Hepatopulmonary syndrome - a liverinduced lung vascular disorder. N Engl J Med. 2008;358:2378-87.

16. Lamia B, Monnet $X$, Teboul JL. Meaning of arterio-venous PCO2 difference in circulatory shock. Minerva Anestesiol. 2006;72:597-604

17. Giovannini I, Chiarla C, Boldrini G, Castagneto M. Calculation of venoarterial CO2 concentration difference. J Appl Physiol. 1993;74:959-64.

18. McHardy GJ. The relationship between the differences in pressure and content of carbon dioxide in arterial and venous blood. Clin Sci. 1967:32: 299-309.

19. Groeneveld A. Interpreting the venous-arterial PCO2 difference. Crit Care Med. 1998;26:979-80

20. Randall HM, Cohen J. Anaerobic CO2 production by dog kidney in vitro. Am J Physiol Content. 1966;211:493-505.

21. Zhang H, Spapen H, Manikis P, Shock DDB-, 1994 undefined. Arteriovenous differences in $\mathrm{PCO} 2$ and $\mathrm{pH}$ are reliable indicators of critical hypoperfusion in septic shock: 13. journals.lww.com.

22. Linden P Van der, Rausin I, AD-A\&, 1995 undefined. Detection of tissue hypoxia by arteriovenous gradient for $\mathrm{PCO} 2$ and $\mathrm{pH}$ in anesthetized dogs during progressive hemorrhage. journals.Iww.com

23. Mekontso-Dessap A, Castelain V, Anguel N, Bahloul M, Schauvliege F, Richard $\mathrm{C}$, et al. Combination of venoarterial PCO2 difference with arteriovenous $\mathrm{O} 2$ content difference to detect anaerobic metabolism in patients. Intensive Care Med. 2002;28:272-7.

24. Groeneveld A, Vermeij C, analgesia LT-A and, 1991 undefined. Arterial and mixed venous blood acid-base balance during hypoperfusion with incremental positive end-expiratory pressure in the pig. europepmc.org.
25. Cuschieri J, Rivers EP, Donnino MW, Katilius M, Jacobsen G, Nguyen HB, et al. Central venous-arterial carbon dioxide difference as an indicator of cardiac index. Intensive Care Med. 2005;31:818-22.

26. van Beest PA, Lont MC, Holman ND, Loef B, Kuiper MA, Boerma EC. Central venous-arterial pCO2 difference as a tool in resuscitation of septic patients. Intensive Care Med. 2013;39:1034-9.

27. Teboul J, Mercat A, Lenique F, CB-C care, 1998 undefined. Value of the venous-arterial PCO2 gradient to reflect the oxygen supply to demand in humans: effects of dobutamine. journals.lww.com

28. Mecher C, Rackow E, Astiz M, medicine MW-C care, 1990 undefined. Venous hypercarbia associated with severe sepsis and systemic hypoperfusion. europepmc.org

29. Vallée F, Vallet B, Mathe O, Parraguette J, Mari A, Silva S, et al. Central venous-to-arterial carbon dioxide difference: an additional target for goaldirected therapy in septic shock? Intensive Care Med. 2008:34:2218-25.

30. Monnet X, Julien F, Ait-Hamou N, ML-C care, 2013 undefined. Lactate and venoarterial carbon dioxide difference/arterial-venous oxygen difference ratio, but not central venous oxygen saturation, predict increase in oxygen. journals.Iww.com

31. Futier E, Robin E, Jabaudon M, Guerin R, Petit A, Bazin J-E, et al. Central venous $\mathrm{O} 2$ saturation and venous-to-arterial $\mathrm{CO} 2$ difference as complementary tools for goal-directed therapy during high-risk surgery. Crit Care. 2010;14:R193.

\section{Publisher's Note}

Springer Nature remains neutral with regard to jurisdictional claims in published maps and institutional affiliations.
Ready to submit your research? Choose BMC and benefit from:

- fast, convenient online submission

- thorough peer review by experienced researchers in your field

- rapid publication on acceptance

- support for research data, including large and complex data types

- gold Open Access which fosters wider collaboration and increased citations

- maximum visibility for your research: over $100 \mathrm{M}$ website views per year

At BMC, research is always in progress.

Learn more biomedcentral.com/submissions 